\title{
Overexpression of Reelin Prevents the Manifestation of Behavioral Phenotypes Related to Schizophrenia and Bipolar Disorder
}

\author{
Cátia M Teixeira*,', Eduardo D Martín², Ignasi Sahún³, Nuria Masachs', Lluís Pujadas', André Corvelo ${ }^{4}$, \\ Carles Bosch', Daniela Rossi ', Albert Martinez', Rafael Maldonado5, Mara Dierssen ${ }^{3}$ and Eduardo Soriano*, I \\ 'Developmental Neurobiology and Regeneration Unit, Institute for Research in Biomedicine, Parc Cientific de Barcelona; Centro de Investigación \\ Biomédica en Red sobre Enfermedades Neurodegenerativas (CIBERNED), and Department of Cell Biology, University of Barcelona, Barcelona, \\ Spain; '2Laboratory of Neurophysiology and Synaptic Plasticity. Albacete Science and Technology Park (PCyTA). Institute for Research in \\ Neurological Disabilities (IDINE), University of Castilla-La Mancha, Albacete, Spain; ${ }^{3}$ Genes and Disease Program, Center for Genomic \\ Regulation (CRG), Barcelona Biomedical Research Park (PRBB) and CIBER de Enfermedades Raras (CIBERER), Barcelona, Spain; \\ ${ }^{4}$ Centro Nacional de Análisis Genómico, Barcelona, Spain; ${ }^{5}$ Departament de Ciències Experimentals i de la Salut, Laboratory of \\ Neuropharmacology, Universitat Pompeu Fabra, Barcelona, Spain
}

\begin{abstract}
Despite the impact of schizophrenia and mood disorders, which in extreme cases can lead to death, recent decades have brought little progress in the development of new treatments. Recent studies have shown that Reelin, an extracellular protein that is critical for neuronal development, is reduced in schizophrenia and bipolar disorder patients. However, data on a causal or protective role of Reelin in psychiatric diseases is scarce. In order to study the direct influence of Reelin's levels on behavior, we subjected two mouse lines, in which Reelin levels are either reduced (Reelin heterozygous mice) or increased (Reelin overexpressing mice), to a battery of behavioral tests: open-field, black-white box, novelty-suppressed-feeding, forced-swim-test, chronic corticosterone treatment followed by forced-swim-test, cocaine sensitization and pre-pulse inhibition (PPI) deficits induced by N-methyl-D-aspartate (NMDA) antagonists. These tests were designed to model some aspects of psychiatric disorders such as schizophrenia, mood, and anxiety disorders. We found no differences between Reeler heterozygous mice and their wild-type littermates. However, Reelin overexpression in the mouse forebrain reduced the time spent floating in the forced-swim-test in mice subjected to chronic corticosterone treatment, reduced behavioral sensitization to cocaine, and reduced PPI deficits induced by a NMDA antagonist. In addition, we demonstrate that while stress increased NMDA NR2B-mediated synaptic transmission, known to be implicated in depression, Reelin overexpression significantly reduced it. Together, these results point to the Reelin signaling pathway as a relevant drug target for the treatment of a range of psychiatric disorders.
\end{abstract}

Neuropsychopharmacology (20II) 36, 2395-2405; doi:10.1038/npp.20II.I53; published online 3 August 20II

Keywords: depression; behavior; cocaine sensitization; pre-pulse inhibition; corticosterone; NR2B

\section{INTRODUCTION}

Schizophrenia, mood, and anxiety disorders are devastating diseases with high prevalence and comorbidity rates (Altamura et al, 2011; Kessler et al, 2005). Despite the

\footnotetext{
*Correspondence: Drs E Soriano or CM Teixeira, Cell and Developmental Biology Programme, Developmental Neurobiology and Regeneration Unit, Institute for Research in Biomedicine (IRB) Barcelona, Parc Científic de Barcelona, Centro de Investigación Biomédica en Red sobre Enfermedades Neurodegenerativas (CIBERNED), and Department of Cell Biology, University of Barcelona, Baldiri Reixac 10, Barcelona E-08028, Spain, Tel: + 3493 4037।I7, Fax: + 3493 4037 I 6, E-mail: eduardo.soriano@irbbarcelona.org or catia.teixeira@irbbarcelona.org

Received 25 March 20 I I; revised 28 June 201 I; accepted 28 June 201 I
}

immense impact of these diseases, knowledge about their pathophysiology is limited. According to the stressdiathesis model, these diseases result from interaction between genetic predisposition and environmental risk factors. Research into how genetic makeup interacts with the environmental factors implicated in the triggering of these diseases is crucial. This implies not only understanding the genetic risk factors but also identifying genetic variations that confer resilience to disease, which may lead to the development of new treatments.

Reelin, an extracellular protein essential for neuronal migration and positioning during development (D'Arcangelo et al, 1995; Tissir and Goffinet, 2003), has received recent attention because of its connection to bipolar disorder and schizophrenia. In fact, comprehensive databases of 
schizophrenia genetic association studies, such as the SZGR (Jia et al, 2010) and the Stanley Foundation Neuropathology Consortium (Kim and Webster, 2009), place Reelin as a top candidate gene associated with schizophrenia. This link is also supported by several studies showing that Reelin levels are reduced in patients with schizophrenia and bipolar disorder (Fatemi et al, 2000; Torrey et al, 2005), altered by antipsychotic, antidepressant, and mood-stabilizing medication (Fatemi et al, 2009), and also reduced following chronic stress (Lussier et al, 2009). Furthermore, Reelin has also been shown to positively modulate adult-neurogenesis (Kim et al, 2002; Pujadas et al, 2010), a process that when disrupted, has been implicated in cognitive and mood-related behavior dysfunctions (Zhao et al, 2008). Noteworthy, several studies found an association between Reelin variants and schizophrenia or bipolar disorder in women only (Goes et al, 2010; Liu et al, 2010; Shifman et al, 2008).

Although these lines of evidence point to a link between Reelin and psychiatric disorders, other studies do not report an effect of Reelin's allelic variants on brain function (Tost et al, 2010). Moreover, there is scarce direct causal evidence of the involvement of this protein in these diseases. Reelindeficient mice (known as reeler) are not suitable for behavioral testing because they show severe motor deficits, and reeler heterozygous mice have been challenged as a suitable model for psychiatric diseases. While some studies have shown that heterozygous reeler have cognitive (Brigman et al, 2006; Qiu et al, 2006a) and sensory-motor deficits as measured in the pre-pulse inhibition test (PPI) (Barr et al, 2008; Tueting et al, 1999), others have failed to find differences (Krueger et al, 2006; Podhorna and Didriksen, 2004; Salinger et al, 2003).

Reelin participates in several functions that are altered in psychiatric diseases, such as neuronal development and synapse formation (D'Arcangelo et al, 1995; Tissir and Goffinet, 2003), glutamatergic neurotransmission (Herz and Chen, 2006), Gsk-3 $\beta$ inhibition (Beffert et al, 2002), and adult neurogenesis (Kim et al, 2002; Pujadas et al, 2010). Given these observations, here we tested whether varying Reelin levels alters behavioral phenotypes related to psychiatric disorders (specifically schizophrenia, mood, and anxiety disorders). For this purpose, we used two mouse lines, the relatively well-characterized heterozygous reeler mice $(\mathrm{rl} /+)$, and a Reelin overexpressing line (Reelin-OE), generated in our laboratory (Pujadas et al, 2010) in which we focused our attention.

Although the design of animal models that relate to all aspects of a specific psychiatric disease is challenging, various models (with different levels of etiological, face, and predictive validity) are available. In this study, we focused on models that, in addition to presenting predictive validity, are based on environmental risk factors and thus present etiological validity, such as chronic stress linked with the development of 'helplessness' and psychostimulant use (Nestler and Hyman, 2010). In all the tests performed, we found no differences between $\mathrm{rl} /+$ mice and their wild-type (WT) littermates, either under basal conditions or after corticosterone, cocaine or $N$-methyl-D-aspartate (NMDA)antagonist treatments. In addition, we show that increased Reelin expression does not alter mood-related behaviors under basal conditions. However, Reelin-OE mice showed reduced time floating in the forced-swim-test after chronic stress, reduced sensitization to cocaine, and reduced disruption of PPI after a NMDA antagonist challenge. In addition, we demonstrate that while chronic stress increased NMDA NR2B-mediated currents in the hippocampus, which were shown to mediate some of the behavioral dysfunctions seen after stress (Wong et al, 2007), Reelin overexpression reduced them. This finding is especially relevant since it has recently been reported that NR2B antagonists have antidepressant properties (Li et al, 2010).

\section{SUBJECTS AND METHODS}

\section{Animals}

Transgenic mice were bred at the Institute for Research in Biomedicine (Barcelona, Spain). Mice were housed in groups (2-6 mice per cage) and maintained on a 12-h light-dark cycle with access to food and water ad libitum. The Reelin-OE mice used in this study have been described previously (Pujadas et al, 2010). This line was obtained by crossing two mouse lines in a tet-off regulated system. The first line (CamKII/tTA) expresses the tTA transactivator under the control of the CamKII- $\alpha$ promoter (Mayford et al, 1996). The second line generated in our laboratory contains a myc-tagged Reelin cDNA construct controlled by a tetO promoter (tetO-rl). Reeler heterozygous mice were obtained from Jackson Laboratories (B6C3Fe a/a-Relnrl/J). Mice were maintained in a C57BL/6J background. Reeler mice were maintained by crossing $\mathrm{rl} /+$ with $\mathrm{C} 57 \mathrm{BL} / 6 \mathrm{~J}$ mice. These mice were backcrossed with C57BL/6J for $>10$ generations. CamKII/tTA mice were previously backcrossed into C57BL/ $6 \mathrm{~J}$ for $>10$ generations in the laboratory of Jesus Avila, who generously provided us with these mice. They were then backcrossed with C57BL/6J mice in our laboratory for five more generations. TetO-rl mice were backcrossed with C57BL/6J for five generations. All mice were at least 8 weeks of age at the start of experiments, and behavioral procedures were conducted during the light phase of the cycle, except for the self-administration procedure, which was done in the dark phase. Females were used in the behavioral experiments, except for the self-administration experiments in which males where used. A detailed table with the groups of mice used in each experiment can be found in the Supplementary information (Supplementary Table S1). Experiments were conducted blind to the treatment condition of the mouse, and in compliance with local animal care protocols.

\section{Immunohistochemistry}

For Reelin immunohistochemistry, mice were perfused transcardially with ice cold $0.1 \mathrm{M}$ phosphate-buffered saline (PBS) and then 4\% paraformaldehyde (PFA). Brains were removed, fixed overnight in $\mathrm{PFA}$, and then transferred to a $30 \%$ sucrose solution and stored at $4{ }^{\circ} \mathrm{C}$. Fifty-micrometer coronal sections were cut and free-floating sections were prepared for immunohistochemistry. For immunodetection of Reelin, sections were blocked for $2 \mathrm{~h}$ at room temperature (RT) with PBS-T containing $10 \%$ of normal goat serum (NGS), $0.2 \%$ of gelatin and anti-mouse unconjugated $\mathrm{F}(\mathrm{ab})_{2}$ fragments $(1: 300$, Jackson ImmunoResearch). Anti-Reelin 
primary antibody (ms, 1:200, Millipore) was incubated overnight at RT with PBS-T with $0.2 \%$ gelatin and $5 \%$ NGS. Sections were washed with PBS-T and then incubated for $2 \mathrm{~h}$ at RT with biotinylated secondary antibody $(1: 200$, Vector Laboratories). After subsequent washes with PBS-T, the sections were incubated for $2 \mathrm{~h}$ at RT with streptavidin-HRP ( $1: 400$, GE Healthcare UK). After washing, the staining was revealed using diaminobenzidine (DAB) and $\mathrm{H}_{2} \mathrm{O}_{2}$, with nickel ammonium sulfate added to the solution. Finally, sections were dehydrated and mounted (Eukitt mounting medium).

\section{Actimetry Box Test}

Locomotor circadian activity was measured in actimetry boxes $(45 \times 45 \mathrm{~cm}$; Harvard Apparatus, Panlab, Spain $)$ placed in a sound-proof cupboard (WT, $n=6$; Reelin-OE, $n=6$ ). Movements were monitored via a grid of infrared beams and used as an index of locomotor activity (counts). Counts were integrated every hour and added to obtain total locomotor activity for a 24-h period, maintaining the $12: 12$-h light-dark schedule. All data were collected with Acti-Track software (Harvard Apparatus).

\section{Corticosterone}

Mice were given corticosterone (Sigma, St Louis, MO) in drinking water $(25 \mathrm{mg} / \mathrm{l})$ for 3 weeks (Gourley et al, 2008). Corticosterone was first diluted in ethanol ( $25 \mathrm{mg}$ of corticosterone in $2 \mathrm{ml}$ of ethanol) before addition to the water. Mice were tested 1 day after corticosterone treatment $\left(\mathrm{WT}_{\text {Reelin-OE}}\right.$, $n=6$; Reelin-OE, $n=5$; $\mathrm{WT}_{\mathrm{rl} /+}, n=8 ; \mathrm{rl} /+, n=12$ ).

\section{Open-Field, Novelty-Suppressed-Feeding, Black and White Box, and Forced-Swim-Test}

General anxiety and depression-like behaviors were tested using the open-field (OF), novelty-suppressed-feeding (NSF), black-white box (BW), and forced-swim-test (FST) tests (Li et al, 2008; Maeng et al, 2008; Santarelli et al, 2003). The OF test consisted of allowing the mice to explore an open white arena $(50 \times 50 \mathrm{~cm})$. The time the mice spent in the center $v s$ the time in the periphery of the arena as well as the total distance traveled were recorded over a 10 -min trial $\left(\mathrm{WT}_{\text {Reelin-OE }}, n=26\right.$; Reelin-OE, $n=13 ; \mathrm{WT}_{\mathrm{rl} /+}, n=12 ; \mathrm{rl} /+$, $n=12)$. In the NSF test, mice were deprived of food for $16 \mathrm{~h}$ and placed in a well-lit arena $(50 \times 50 \mathrm{~cm}$, covered with sawdust) with a food pellet in the center. Latency in feeding was recorded $\left(\mathrm{WT}_{\text {Reelin-OE }}, n=26\right.$; Reelin-OE, $n=13$; $\mathrm{WT}_{\mathrm{rl} /+}$, $n=7 ; \mathrm{rl} /+, n=10)$. In the BW box test, mice were placed in the dark compartment of a box $(20 \times 20 \mathrm{~cm})$ connected to a well-lit, white compartment $(25 \times 25 \mathrm{~cm})$. The time the mice spent in the white compartment was recorded during the $5 \mathrm{~min}$ of the test $\left(\mathrm{WT}_{\text {Reelin-OE }}, n=12\right.$; Reelin-OE, $n=13$; $\left.\mathrm{WT}_{\mathrm{rl} /+}, n=6 ; \mathrm{rl} /+, n=6\right)$. The FST is a measure of depression-like behavior and is used to test antidepressant activity. In the FST, mice were placed for $5 \mathrm{~min}$ in a 51 beaker (diameter: $20 \mathrm{~cm}$; water depth: $12 \mathrm{~cm}$ ) filled with warm water $\left(27^{\circ} \mathrm{C}\right)$ until the 31 mark. The amount of time the mice spent floating during the last $4 \mathrm{~min}$ of the trial was recorded ( $\mathrm{WT}_{\text {Reelin-OE }}, n=26$; Reelin-OE, $n=13 ; \mathrm{WT}_{\mathrm{rl} /+}$, $n=6 ; \mathrm{rl} /+, n=6)$.

\section{Cocaine Sensitization}

Mice used in the OF test were subsequently subdivided and used in the cocaine sensitization experiment ( $\mathrm{WT}_{\text {saline, }} n=9$; Reelin- $\mathrm{OE}_{\text {saline, }} n=5 ; \mathrm{WT}_{\text {cocaine, }} n=17 ; \mathrm{Reelin}-\mathrm{OE}_{\text {cocaine, }}$ $n=8 ; \mathrm{WT}_{\text {saline }-\mathrm{rl} /+}, n=6 ; \mathrm{rl} /+_{\text {saline, }} n=6 \mathrm{WT}_{\text {cocaine }-\mathrm{rl} /+}$, $n=6 ; \mathrm{rl} /+_{\text {cocaine, }} n=6$ ). See Supplementary Table S1 for a detailed description of the groups of animals used. Thus, the first day of habituation corresponds to the OF trial. One week after being subjected to the previous tests, mice were habituated to the OF box for an additional $20 \mathrm{~min}$ (habituation day 2). Starting the following day, separate groups of mice were injected intraperitoneally with either cocaine $(10 \mathrm{mg} / \mathrm{kg}$ in $0.9 \% \mathrm{NaCl})$ or saline $(0.9 \% \mathrm{NaCl})$ for 5 consecutive days and immediately placed in the OF box. Locomotion was recorded for 20 min using the Smart Junior software (Panlab, Spain). Two weeks after the last cocaine injection, mice received a challenge injection and were placed back in the OF box as previously described (Maeng et al, 2008).

\section{Self-Administration}

The procedure for cocaine self-administration used in this work was previously described in detail (Boeuf et al, 2009). Briefly, mice were anaesthetized and implanted with an intravenous catheter in the jugular vein. Catheter patency was evaluated at the end of the experiment by infusing $0.1 \mathrm{ml}$ of thiopental $(5 \mathrm{mg} / \mathrm{ml})$ through the catheter. Mice that did not show signs of anesthesia $3 \mathrm{~s}$ after infusion were removed from the analysis. Three days after surgery, mice were trained to nose-poke (operant chambers ENV-307A-CT, Med-Associates) to acquire intravenous self-administration of cocaine $(0.5 \mu \mathrm{g} / \mathrm{ml})$ on a fixed ratio 1 schedule of reinforcement, during 12 days of daily 1 -h sessions (Reelin-OE $n=5$; WT $n=5)$. The motivational value of cocaine was then assessed using a progressive ratio schedule of reinforcement (escalated series: 1-2-3-5-12-18-27-40) in a single 3-h session.

\section{Rotor-Rod}

Mice were first habituated for $1 \mathrm{~min}$ to walk on a rotor-rod at 4 r.p.m. (WT, $n=5$; Reelin-OE, $n=5$ ). They were then given three trials with the rotor-rod accelerating from 4 to 40 r.p.m. over $5 \mathrm{~min}$. The average latency to fall was calculated for each mouse.

\section{PPI of Acoustic Startle Response}

The PPI of acoustic startle response was measured with a startle response apparatus (Harvard Apparatus). Each mouse was habituated to the equipment by being placed in the restraint device for 5 in a day during 3 days. On the test day, mice were allowed a 15-min habituation to the apparatus with background noise of $62 \mathrm{~dB}$ and then exposed to six blocks of seven trial types in pseudo-random order with 30-s inter-trial intervals. The eight trial types were as follows: trial 1 (startle-only trial), $40 \mathrm{~ms}$ of a $120 \mathrm{~dB}$, $8000 \mathrm{~Hz}$ sound; trials 2-7 (pre-pulse (PP) trials), $40 \mathrm{~ms}$ of a $120 \mathrm{~dB}, 8000 \mathrm{~Hz}$ sound preceded for $140 \mathrm{~ms}$ by a $20 \mathrm{~ms} \mathrm{PP}$ sound of $70,74,78,82,86$, or $90 \mathrm{~dB}$; and trial $8,62 \mathrm{~dB}$ background noise. The startle response was recorded for $65 \mathrm{~ms}$, with measurements every $1 \mathrm{~ms}$ from the onset 
of the startle stimulus. The maximum startle amplitude recorded during the $65 \mathrm{~ms}$ sampling window was used as the dependent variable. The PPI for each PP trial was defined as 100 ((startle amplitude on PP trials/startle amplitude on pulse alone trials) $\times 100)$. One week after baseline PPI testing, the mice were injected with MK-801 $(0.15 \mathrm{mg} / \mathrm{kg}$ in $0.9 \% \mathrm{NaCl}$ ) and then retested for PPI 10 min later. One week later, the same group was tested after a $0.3 \mathrm{mg} / \mathrm{kg} \mathrm{MK}-801$ injection $\left(\mathrm{WT}_{\text {Reelin-OE }}, n=7\right.$; Reelin-OE, $n=10 ; \mathrm{WT}_{\mathrm{rl} /+}$, $n=9 ; \mathrm{rl} /+, n=9)$.

\section{Electrophysiology}

Transverse brain slices ( $400 \mu \mathrm{m}$ thickness) were prepared as described previously (Martin and Buno, 2003) and incubated for $>1 \mathrm{~h}$ at RT $\left(21-24^{\circ} \mathrm{C}\right)$ in ACSF. The ACSF contained the following (in $\mathrm{mM}$ ): $\mathrm{NaCl} 124, \mathrm{KCl} 2.69, \mathrm{KH}_{2} \mathrm{PO}_{4} 1.25, \mathrm{MgSO}_{4} 2$, $\mathrm{NaHCO}_{3} 26, \mathrm{CaCl}_{2} 2$ and glucose 10 , and was gassed with $95 \%$ $\mathrm{O}_{2}$ and $5 \% \mathrm{CO}_{2}$. Slices were transferred to an immersion recording chamber and superfused $(2.5 \mathrm{ml} / \mathrm{min})$ with equilibrated ACSF. Extracellular field excitatory postsynaptic potentials (fEPSPs) were recorded with a glass microelectrode (impedances: 2-3 M ; filled with $1 \mathrm{M} \mathrm{NaCl}$ ) positioned in stratum radiatum area CA1. Evoked fEPSPs were elicited by stimulation of the Schaeffer collateral fibers with an extracellular bipolar nichrome electrode via a 2100 isolated pulse stimulator (A-M Systems, Carlsborg, WA). The responses to paired-pulse stimulation at a range of interpulse intervals (25$400 \mathrm{~ms}$ ) were used to measure paired-pulse facilitation. Data were transferred to the hard disk of a Pentium-based computer using a DigiData $1440 \mathrm{~A}$ interface and the pCLAMP 10.0 software (Molecular Devices, Union City, CA). To measure the contribution of NMDA receptors to fEPSPs, we performed the experiment in the presence of $50 \mu \mathrm{M}$ bicuculline to isolate EPSPs from gamma-aminobutyric acid A-mediated inhibitory synaptic transmission. Application of AP5 $(50 \mu \mathrm{M})$, an antagonist of NMDARs, abolished fEPSPs, thereby confirming that the fEPSPs recorded were mediated through NMDARs. In this condition, 6- cyano-7-nitroquinoxaline-2, 3-dione (CNQX; $20 \mu \mathrm{M})$ in $\mathrm{Mg} 2+$-free external solution was added to pharmacologically isolated NMDA fEPSC components. Train stimuli at $100 \mathrm{~Hz}$ were used to assess the synaptic activation of the NMDA receptors by high-frequency afferent stimulation. To measure the contribution of NR2B receptors, we performed recordings in the presence of $3 \mu \mathrm{M}$ of Ifenprodil. All drugs were purchased from Sigma, except CNQX, DL-2-amino-5-phosphopentanoic acid (AP5), Ifenprodil and Bicuculline, which were all from Tocris Cookson (Bristol, UK).

\section{Statistical Analysis}

Statistical differences were established using a two-tailed Student's $t$-test or ANOVA followed by an LSD post hoc test. Data are expressed as mean \pm SEM.

\section{RESULTS}

\section{Reeler Heterozygous Mice Do Not Exhibit Behavioral Phenotypes Related to Psychiatric Disorders}

Contradictory findings have been reported regarding behavioral alterations of Reeler heterozygous mice (Barr et al,
2008; Brigman et al, 2006; Krueger et al, 2006; Podhorna and Didriksen, 2004; Qiu et al, 2006a; Salinger et al, 2003; Tueting et al, 1999). In order to assess whether these mice present behavioral alterations related to psychiatric disorders, we first subjected them to a battery of tests currently used as anxiety (OF, NSF, and BW box) and depression (FST) models. Heterozygous reeler mice $(\mathrm{rl} /+)$ showed no significant differences from their WT littermates in any of the tests performed (Figures 1a-e).

Although diseases like schizophrenia and bipolar disorder have a significant heritable component, interactions between genes and environmental risk factors make a significant contribution to the development of these diseases. One of the major environmental factors that precipitates depression as well as schizophrenic and bipolar disorder episodes is stress (Krishnan and Nestler, 2008). In order to study stress-associated behavioral dysfunctions in mice, we subjected them to a chronic treatment of the stressassociated hormone corticosterone. Next, we used the FST as a measure of developed helplessness-like behavior (Gourley and Taylor, 2009). After 3 weeks of corticosterone administration, there were no differences between stressed WT and heterozygous reeler mice (Figure 1f).

Dopamine agonists and NMDA antagonists induce behavioral dysfunctions, such as PPI and working-memory deficits, similar to those observed in schizophrenia (Geyer and Markou, 1995; Krystal et al, 1994). In addition, the hypothesis that schizophrenia might be related to dopaminergic or glutamatergic dysfunction (Belforte et al, 2009) led to the development of mouse models based on the modulation of these neurotransmitters (Geyer and Markou, 1995; Nestler and Hyman, 2010). Locomotion sensitization to psychostimulants provides a good predictive value of the efficacy of antipsychotic and mood-stabilizing drugs and this approach has been used in schizophrenia and mania research (Geyer and Markou, 1995; Nestler and Hyman, 2010). In order to study manic-like behavior and positive symptoms of schizophrenia in mice, we used the cocaine sensitization model (Figures 1g-h). Heterozygous reeler mice receiving saline treatment had locomotion values similar to those of their WT littermate controls throughout the experiment (Figure 1g). As expected, cocaine-treated $\mathrm{rl} /+$ and WT mice increased their locomotion over the course of the treatment, and we found no significant differences between genotypes (Figure $1 \mathrm{~h}$; day: $\left.\mathrm{F}_{(7,70)}=8.54, p<0.001\right)$. A comparison of locomotion on day 19 between all the groups indicated that animals receiving cocaine showed higher locomotion values, independently of the genotype (drug: $\mathrm{F}_{(1,19)}=11.49, p<0.01$; LSD test $p<0.01$ ).

Deficits in PPI may indicate an incapacity to filter irrelevant information and they are observed in schizophrenic patients (Braff et al, 2001). Thus, PPI has been used as a tool to study schizophrenic-related behavior in mice as it shows good face and predictive value (Geyer and Markou, 1995; Miyakawa et al, 2003). In addition, previous studies have shown that heterozygous reeler mice present PPI deficits (Barr et al, 2008). We thus examined whether PPI was modified in heterozygous reeler mice. No significant disruption of PPI in untreated $\mathrm{rl} /+$ was detected when compared with their WT littermate controls (Figures $1 \mathrm{i}-\mathrm{j}$ and Supplementary Figure S3a). Startle amplitudes are shown in Supplementary Figure S2. 

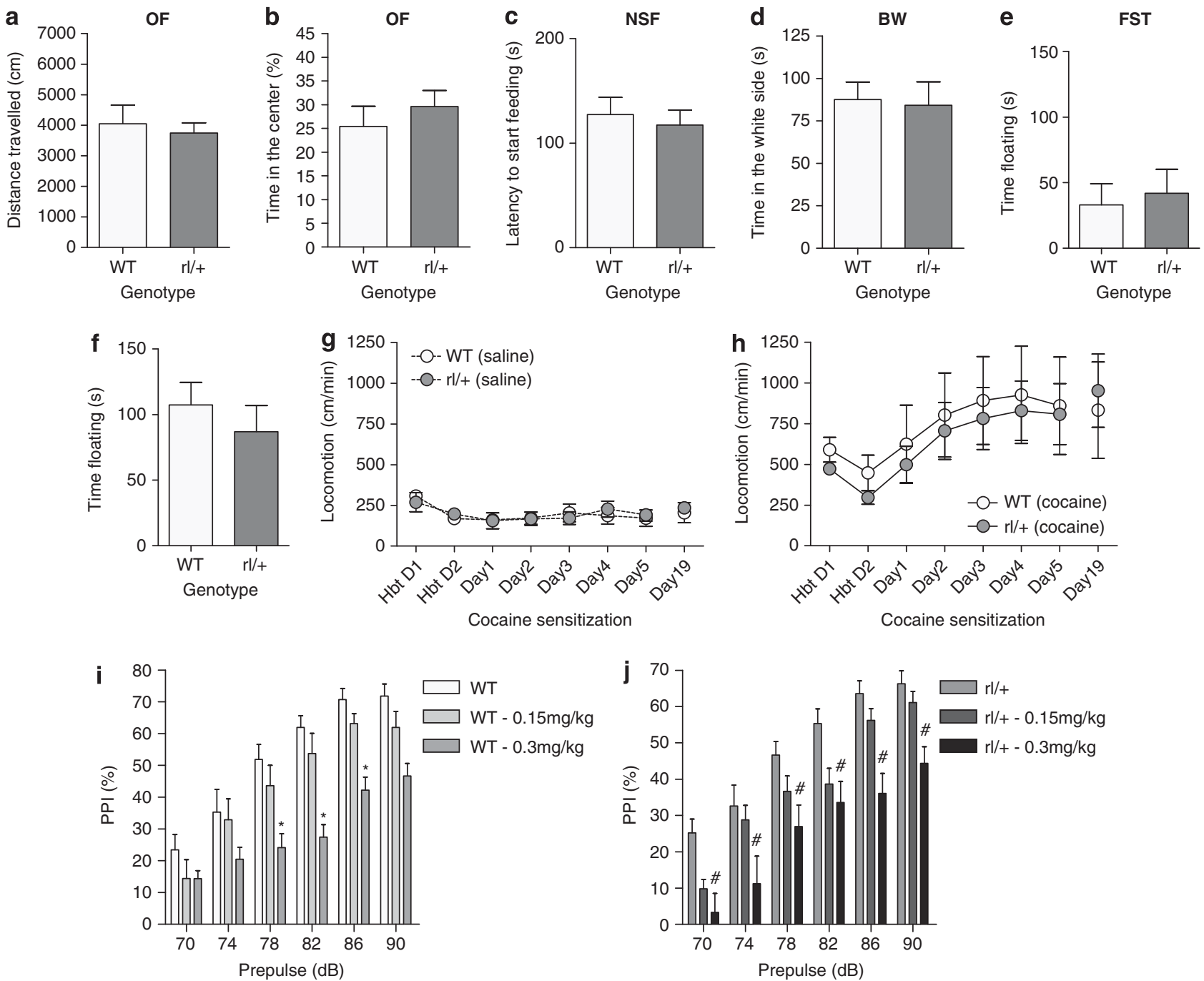

Figure I Behavioral characterization of reeler heterozygous $(\mathrm{rl} /+)$ mice $(\mathrm{a}-\mathrm{e})$ Characterization of anxiety- and depression-like behaviors in $\mathrm{rl} /+$ mice. There were no significant differences between $\mathrm{rl} /+$ and WT mice in the distance travelled (a) and in the time spent in the center (b) in the open-field test (OF). Nor there were differences in the latency to feed in the novelty-suppressed feeding test (c: NSF), in the time spent on the white compartment of the black and white box (d: BW) or in the time spent floating in the forced-swim-Test (e: FST). ( $f$ ) After 3 weeks of corticosterone administration, there were no significant differences in the time spent floating in the FST between $\mathrm{rl} /+$ and WT mice. $(\mathrm{g}, \mathrm{h}$ ) Cocaine sensitization in $\mathrm{rl} /+$ mice. (g) Locomotion values for $\mathrm{rl} /+$ and WT mice treated with saline. (h) Sensitization to continuous cocaine administration in $\mathrm{rl} /+$ and WT mice. (i) Reelin heterozygous WT littermate controls showed significantly reduced PPI after treatment with $0.3 \mathrm{mg} / \mathrm{kg}$ MK-80I at PP levels of 78-86 dB. (j) There was a significant effect of the dose on the disruption of PPI in $\mathrm{rl} /+$ mice. PPI was significantly disrupted with the $0.3 \mathrm{mg} / \mathrm{kg}$ dose (\#). In figure (j), there was a significant effect of the dose, as shown by ANOVA. A posterior LSD test showed that the $0.3 \mathrm{mg} / \mathrm{kg}$ dose was significantly different from the other treatments. Significant differences were established at $* p<0.05$. Data are presented as mean \pm SEM.

NMDA antagonist-induced deficits in PPI are used as a model of the positive symptoms of schizophrenia and have good predictive value of the efficacy of anti-psychotic medication (van den Buuse, 2010). Here, we proceeded to treat $\mathrm{rl} /+$ mice and their respective WT littermates with the NMDA antagonist, MK-801, 10 min before testing them for PPI. MK-801 disrupted PPI in a dose-dependent manner in WT (Figure 1i) and rl/ + animals (Figure 1j). In rl/ + WT littermates, there was a significant dose by PP level interaction, showing that PPI was significantly disrupted when using $0.3 \mathrm{mg} / \mathrm{kg}$ of $\mathrm{MK}-801$ on the PP levels of $78-86 \mathrm{~dB} \quad\left(\mathrm{PP} \times\right.$ dose: $\mathrm{F}_{(10,120)}=2.96, p<0.01$; LSD test, $p<0.05$ ). At $0.3 \mathrm{mg} / \mathrm{kg}$, MK-801 also significantly disrupted
PPI in $\mathrm{rl} /+$ mice (dose: $\mathrm{F}_{(2,24)}=9.72, p<0.0001$; LSD test $p<0.05)$. Together, these results suggest that reeler heterozygous mice do not show behavioral alterations related to psychiatric disorders.

\section{Reelin-OE Mice Display Normal Anxiety- and Depression-Related Behaviors Under Basal Conditions}

Given that $\mathrm{rl} /+$ mice fail to show behavioral alterations, we tested whether Reelin overexpression is involved in the modulation of schizophrenia-, mood-, and anxiety-related behavioral phenotypes. For this purpose, we used a line generated in our laboratory (Pujadas et al, 2010) that 
overexpresses Reelin under the control of the CAMKII- $\alpha$ promoter (Reelin-OE). This promoter drives expression exclusively in the postnatal brain in excitatory forebrain neurons. These animals showed widespread expression of Reelin in pyramidal neurons of the neocortex and hippocampus, as well in most striatal neurons (Figures 2a and b). We have previously shown that this 4-6-fold increase in Reelin expression leads to over-activation of the Reelin pathway, as seen by an increase in Dabl phosphorylation (Pujadas et al, 2010). In contrast to the dramatic cytoarchitectonic alterations and severe motor deficits found in reeler mice (Reelin knock-out), no gross anatomic or behavioral abnormalities were observed in Reelin-OE mice. These mice showed increased activity during the dark phase of their circadian rhythm (Figure 2c; 22-8h: $\left.t_{(10)}=-2.40, p<0.05\right)$ and normal locomotion in the OF test (Figure 2d), thereby indicating the absence of motor deficits.

Next, we tested whether anxiety-related behaviors were altered in the Reelin-OE mice. We found no differences between Reelin-OE mice and their littermate controls in the OF (Figures $2 \mathrm{~d}$ and e), in the NSF (Figure $2 \mathrm{f}$ ) or in the FST (Figure 2h). However, Reelin-OE animals showed reduced anxiety-like behavior in the BW box (Figure 2g; $\left.t_{(23)}=-2.27, p<0.05\right)$.

\section{Reelin-OE Mice Show Reduced Time Floating in the FST After Chronic Corticosterone Treatment and also Hyperlocomotion Induced by Psychostimulants}

To test whether environmental risk factors like stress and psychostimulant abuse affect Reelin-OE mice differently, we next tested these mice in the FST after chronic corticosterone treatment and in the cocaine sensitization model. Corticosterone-treated WT mice spent more time floating in the FST than controls. This effect was abolished by Reelin overexpression, thereby indicating that Reelin-OE mice were less susceptible to corticosterone-induced helplessness-like behavior (Figure 3a; genotype $\times$ treatment: $\mathrm{F}_{(1,27)}=7.04, p<0.05$; LSD test $\left.p<0.05\right)$. These data suggest that Reelin overexpression protects against the development of behavioral dysfunctions induced by chronic stress.

In the cocaine sensitization model, no differences in locomotion were observed between the Reelin-OE and WT mice receiving saline injections. This observation indicates that there were no differences in novelty-induced hyperlocomotion or in habituation to the novel environment (Figure 3b). On the first day of sensitization, cocaineinjected Reelin-OE mice exhibited locomotion values identical to those of WT and Reelin-OE animals injected with saline (Figures $3 \mathrm{c}$ and d). In contrast, WT mice injected with cocaine showed significantly higher locomotion values than all the other groups (genotype $\times$ drug: $\mathrm{F}_{(1,35)}=4.92, p<0.05$; LSD test $\left.p<0.05\right)$. Over the course of the experiment, WT mice injected with cocaine showed a dramatic increase in locomotion activity. In contrast, Reelin-OE mice showed less sensitivity to continued cocaine administration than their WT littermates (Figure 3e; genotype $\times$ day: $\quad \mathrm{F}_{(7,161)}=11.80, \quad p<0.0001 ; \quad$ LSD test $p<0.05)$. Comparison of the locomotion values at day 19 between cocaine- and saline-treated animals shows that cocaine-treated WT mice presented significantly higher locomotion values than saline controls and cocaine-treated Reelin-OE mice (Figure 3f; genotype $\times$ drug: $\mathrm{F}_{(1,35)}=5.99$, a

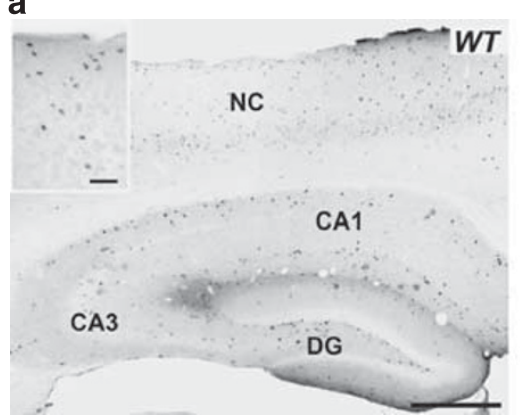

b

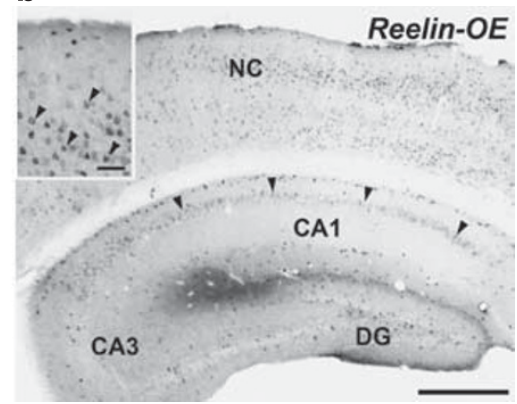

C

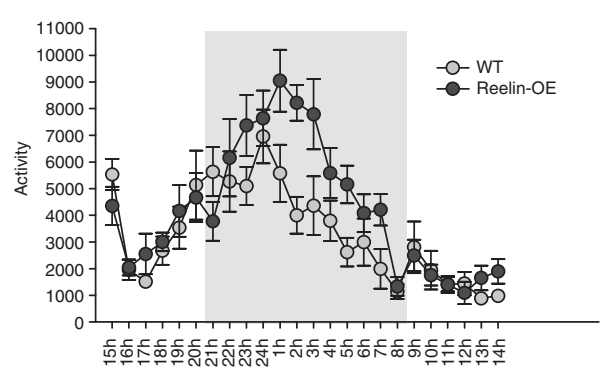

BW

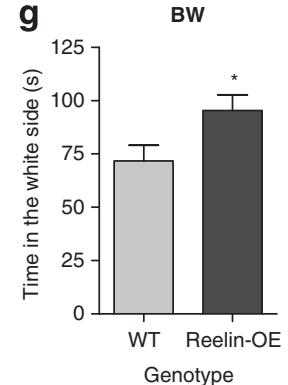

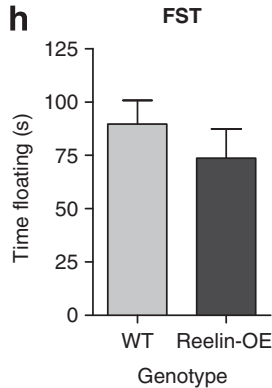

Figure 2 General characterization of Reelin-OE mice. (a, b) Reelin expression in Reelin-OE mice (b) was higher than in WT mice (a) throughout the postnatal forebrain, including the hippocampus (CAI, CA3, DG) and the cortex (NC). Arrowheads-Reelin overexpressing neurons. Scale bar: $500 \mu \mathrm{m}$. Scale bar of insets: $100 \mu \mathrm{m}$. (c) Reelin-OE mice showed increased activity during the dark phase of the light cycle. (d-h) Characterization of anxiety- and depression-like behaviors in Reelin-OE mice. There were no significant differences between WT and Reelin-OE mice in most tests (d-e: OF; f: NSF; h: FST). Reelin-OE mice spent significantly more time in the white compartment in the Black-White box test (g: BW). Significant differences were established at $*_{p}<0.05$. Data are presented as mean \pm SEM. 
a
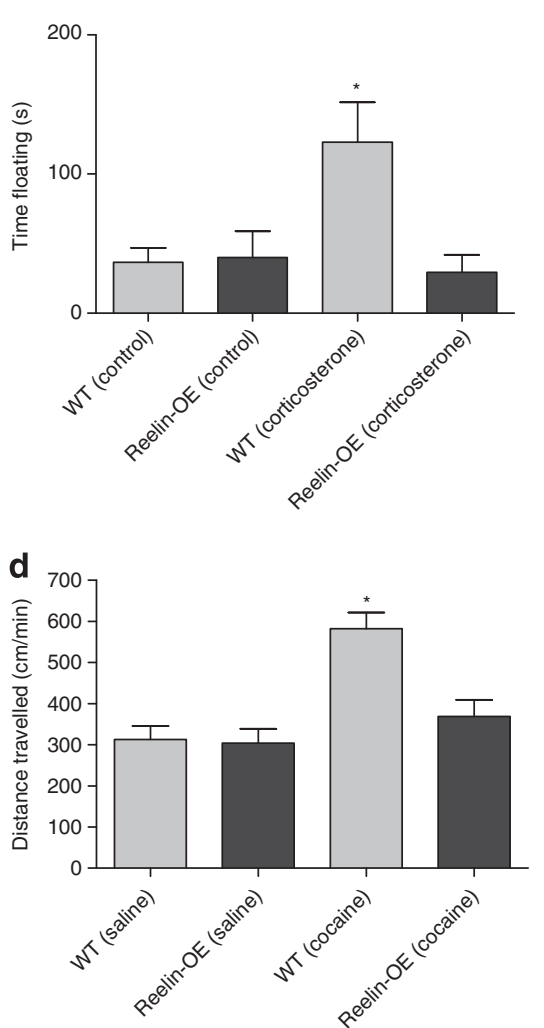

b

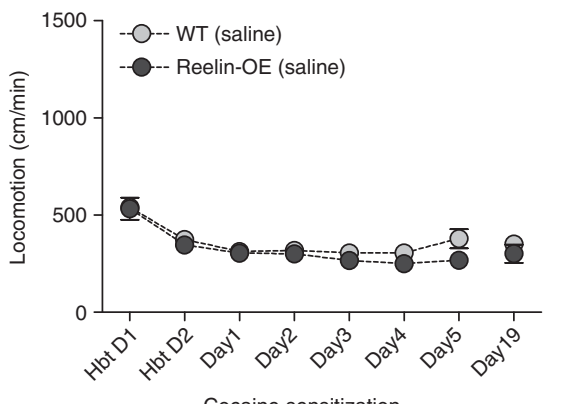

Cocaine sensitization

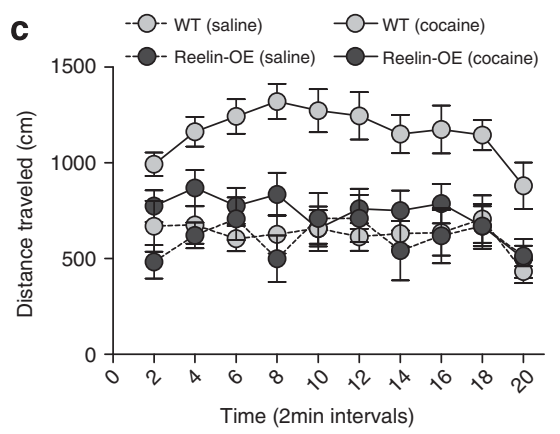

240

Figure 3 Reduced helplessness-like behavior after corticosterone treatment and cocaine sensitization in Reelin-OE mice. (a) Reelin-OE mice spent less time floating in the FST than WT animals after corticosterone treatment. (b-f) Cocaine sensitization in Reelin-OE mice. (b) There were no differences in locomotion between Reelin-OE mice and their WT controls injected with saline. (c, d) After a single cocaine injection, locomotion of the Reelin-OE mice did not differ from that shown by saline controls during the $20 \mathrm{~min}$ of test. (e) Reelin-OE mice presented less cocaine sensitization. ( $f$ ) Comparison of the locomotion values at day 19. Cocaine-treated WT mice showed locomotion values significantly higher than saline controls and cocaine-treated Reelin-OE mice. Significant differences were established at $* p<0.05$. Data are presented as mean \pm SEM.

$p<0.05$; LSD test $p<0.05)$. These findings indicate that the behavioral dysfunctions induced by cocaine were dramatically blocked by Reelin overexpression. The differences observed in cocaine sensitization were not due to differences in the rewarding effects of cocaine or in motor performance, measured in the cocaine self-administration paradigm and in the rotor-rod, respectively (Supplementary Figures S1a-c in Supplementary information).

Taken together, these data show that Reelin-OE mice are resistant to the psychomotor effects of chronic psychostimulant administration.

\section{Reelin-OE Prevents PPI Deficits Induced by NMDA Antagonists}

PPI deficits are an especially relevant schizophrenia endophenotype given that they can be easily tested in mice. We found no differences in PPI between untreated WT and Reelin-OE mice (Figures $4 \mathrm{a}$ and $\mathrm{b}$ and Supplementary Figure S3d). Startle amplitudes are shown in Supplementary Figure S2. However, significantly lower PPI levels were observed in WT mice (Reelin-OE littermates) treated with $0.3 \mathrm{mg} / \mathrm{kg}$ of MK-801 compared with the control and the $0.15 \mathrm{mg} / \mathrm{kg}$ groups (Figure 4a; dose: $\mathrm{F}_{(2,18)}=4.01, p<0.05$; LDS test $p<0.05$ ), while no differences between treated and control Reelin-OE were detected (Figure $4 \mathrm{~b}$ ). This finding
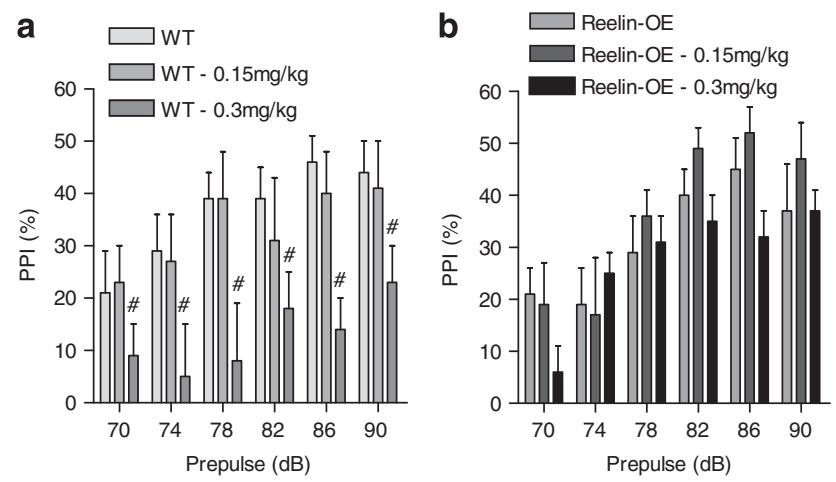

Figure 4 Increased resilience after a MK-80I challenge in Reelin-OE mice. (a) PPI in WT mice (Reelin-OE littermates) was significantly disrupted at a dose of $0.3 \mathrm{mg} / \mathrm{kg}(\#)$. In figure (a), there was a significant effect of the dose, as shown by ANOVA. A posterior LSD test showed that the $0.3 \mathrm{mg} / \mathrm{kg}$ dose was significantly different from the other treatments. (b) MK-80I treatment did not affect PPI in Reelin-OE mice. Data are presented as mean \pm SEM.

indicates that Reelin-OE mice are more resilient to a NMDA antagonist challenge. This observation is highly relevant because this test has good predictive value for the efficacy of antipsychotic medication (van den Buuse, 2010). 


\section{Reelin Increases Glutamatergic Transmission In Vivo}

Reelin controls glutamatergic neurotransmission during development (Chen et al, 2005; Groc et al, 2007; Herz and Chen, 2006; Qiu et al, 2006b) and LTP is enhanced in Reelin-OE mice (Pujadas et al, 2010). Given that NMDA receptor hypofunction is often observed in schizophrenic patients (Coyle, 1996), we proceeded to analyze NMDAmediated transmission in Reelin-OE mice. We first analyzed basal synaptic transmission in acute hippocampal slices from these mice and WT littermates. After stimulating Schaeffer collaterals with isolated stimuli of increasing intensity, neurons were recorded in the CA1 region. Extracellular field recordings showed that Reelin-OE CA1 neurons exhibited increased fEPSP responses, which were statistically significant at high stimulus strengths (Figure 5a; $V_{20}: t_{(20)}=-2.18, p<0.05$; See also Supplementary Figure S4 in Supplementary information). Using fEPSP recordings evoked by a three-stimulus train $(100 \mathrm{~Hz})$, we next examined whether synaptic activation of NMDA receptors was normal in Reelin-OE mice. After the second and third stimuli in the train, the NMDA receptor-mediated component of fEPSP (pharmacologically isolated) was significantly reduced in the WT slices when compared with the first stimuli (Figure $5 \mathrm{~b} ; t_{(6)}=3.83, p<0.01$ ). In contrast, there was a significant increase after the second stimulus in the Reelin-OE mice (Figure $5 \mathrm{~b} ; t_{(5)}=-2.61, p<0.05$ ). These observations indicate that Reelin overexpression potentiates NMDA-dependent glutamatergic neurotransmission, a process that is altered in several psychiatric disorders (Coyle, 1996).

\section{Reelin Decreases NMDA NR2B-Mediated Currents}

Reelin is involved in the NR2B to NR2A developmental switch (Groc et al, 2007). Given that NR2B antagonists act as antidepressant drugs ( $\mathrm{Li}$ et al, 2010), we next studied NR2B activity in WT and Reelin-OE mice. Perfusion of Ifenoprodil, a specific NR2B antagonist, reduced

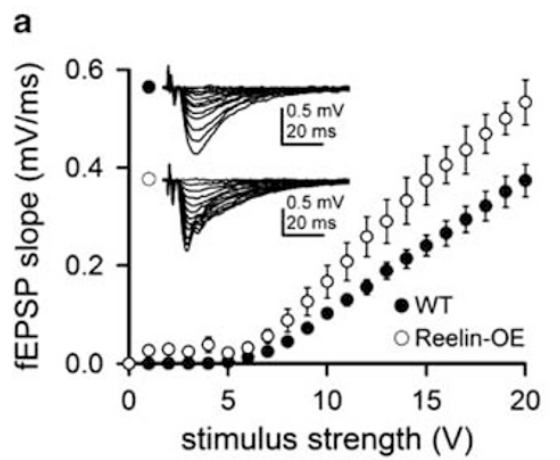

b
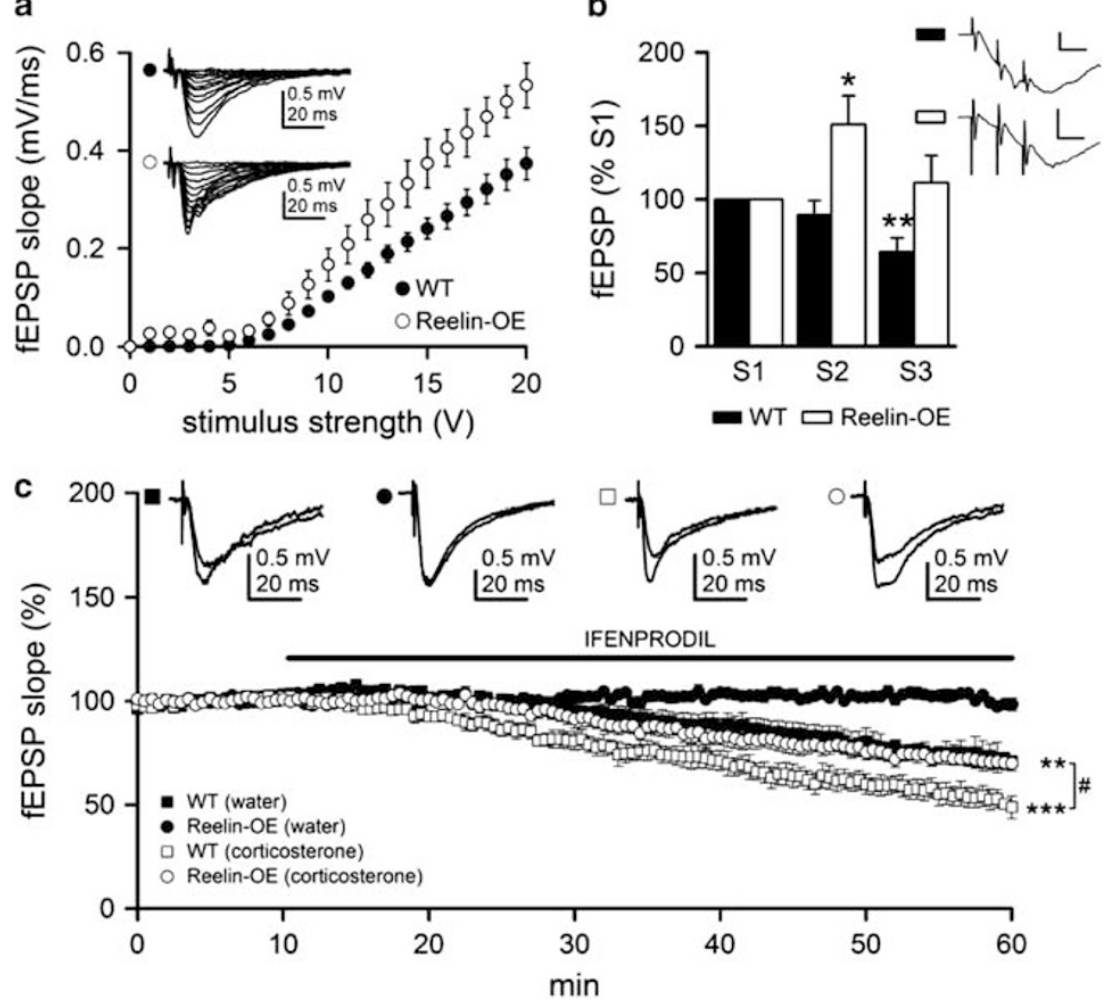

Figure 5 Reelin overexpression modifies synaptic activation of NMDA receptors and the function of NR2B subunit. (a) fEPSP slopes for WT (filled circle, $n=12$ slices from three mice) and Reelin-OE (open circle, $n=10$ slices from three mice) slices for a given range of stimulus intensities. Note that Reelin-OE CAI neurons tended to exhibit increased fEPSP responses. Inset shows representative fEPSPs recorded in the stratum radiatum, and evoked by stimulation of the Schaffer collateral-commissural pathway with different intensities in WT (top) and Reelin-OE (bottom) mice. (b) Summary data showing mean NMDA-isolated fEPSP slopes in WT (filled bar; $n=7$ slices from three mice) and Reelin-OE (open bar; $n=6$ slices from three mice) slices. The fEPSP slope was significantly smaller in the WT mice for the third stimulus and significantly larger in the Reelin-OE mice for the second stimulus (compared with its respective first stimulus). Significant differences were established at $* p<0.05$ and $* * *<0.0$ I. Inset shows representative field responses of NMDA component evoked by a $100 \mathrm{~Hz}$ train (three stimuli) in WT (top trace) and Reelin-OE (bottom trace), recorded in the presence of $20 \mu \mathrm{M}$ CNQX to block the AMPA component. Calibration: $0.5 \mathrm{mV}, 10 \mathrm{~ms}$. (c) Time course of $3 \mu \mathrm{M}$ Ifenprodil effects on normalized mean NMDAR-mediated fEPSP slopes evoked by Schaeffer collateral stimulation in WT control (filled square, $n=6$ slices from three mice), WT treated with corticosterone (open square, $n=6$ slices from three mice), Reelin-OE control (filled circles, $n=6$ slices from three mice), and Reelin-OE treated with corticosterone (open circles, $n=6$ slices from three mice) slices. Inset shows representative fEPSPs recorded in the absence or presence of Ifenprodil. Significant differences were established at $* * *<0.0$ I and ${ }^{*} * * * 0.00$ I (with respect to pre-Ifenprodil perfusion baseline slope values) and ${ }^{*} p<0.05$ (between WT and Reelin-OE treated with corticosterone). Data are presented as mean $\pm \mathrm{SEM}$. 
NMDA-mediated fEPSPs slopes by $30 \%$ in control WT slices $\left(t_{(5)}=3.35, p<0.01\right)$ while no changes were detected in Reelin-OE slices (Figure 5c). These observations indicate that Reelin overexpression in vivo leads to a dramatic hypofunction of NR2B-containing NMDARs.

Next, we analyzed NMDA-mediated neurotransmission in WT and Reelin-OE mice treated with corticosterone (Figure 5c; see also Supplementary Figure S5 in Supplementary information). In corticosterone-treated $\mathrm{WT}$ mice, electrophysiological recordings in the presence of Ifenprodil showed a marked reduction in NMDARs-mediated fEPSPs (nearly $50 \%$ of baseline; Figure $5 c ; t_{(5)}=6.96, p<0.001$ ). Interestingly, Reelin-OE mice treated with corticosterone exhibited fEPSPs that were indistinguishable from those of WT controls (Figure $5 c ; t_{(10)}=-2.39, p<0.05$ ). Given that $\mathrm{NR} 2 \mathrm{~B}$ is upregulated after stress and NR2B inhibition is sufficient to prevent behavioral deficits induced by stress (Li et al, 2010; Wong et al, 2007), our results suggest that Reelin overexpression increases resilience to stress through NR2B downregulation.

\section{DISCUSSION}

In order to study the role of Reelin in the modulation of behavioral phenotypes related to schizophrenia, mood, and anxiety disorders, we used two mouse lines that express different levels of Reelin: Reelin overexpressing mice (Reelin-OE) and heterozygous Reelin knock-out mice $(\mathrm{rl} /+)$. Under basal conditions, Reelin-OE and $\mathrm{rl} /+$ mice presented mood-related behaviors similar to those of WT mice. However, when challenged with environmental stressors implicated in the genesis of psychiatric diseases-chronic stress and psychostimulant abuse-ReelinOE mice were more resilient. These mice spent less time floating in the FST after chronic corticosterone treatment and less hyperlocomotion induced by cocaine. Furthermore, they were protected against the PPI deficits induced by NMDA antagonists. In addition, we show that Reelin overexpression enhanced glutamatergic transmission while simultaneously reducing NR2B-subunit-dependent NMDA currents.

Intense research effort is underway to identify resilience and risk factors involved in the pathophysiology of psychiatric diseases. Although epidemiological studies provide us with a list of candidate genes, further studies are necessary to identify whether these genes have a causative or protective role or even no role at all. Previous studies have shown that Reelin, an extracellular protein extensively studied during development because of its roles in cortical lamination, is downregulated in patients with several psychiatric diseases and is associated with schizophrenia (Fatemi et al, 2000; Jia et al, 2010; Kim and Webster, 2009). However, behavioral studies on the function of this protein have been hampered by the fact that reeler mice have severe motor deficits. In fact, the absence of Reelin in humans causes a neurological disorder-lissencephaly-characterized by the lack of development of the brain gyri and sulci, which leads to severe neurological impairments (Hong et al, 2000). In contrast, reeler heterozygous mice, which have no motor deficits (Podhorna and Didriksen, 2004), have been studied in some detail. These mice have mild cognitive deficits and higher anxiety levels, with PPI deficits being the most consistently documented behavioral phenotype related to psychiatric diseases (Barr et al, 2008; Tueting et al, 1999). However, these findings have not been replicated by other studies (Podhorna and Didriksen, 2004; Salinger et al, 2003). Furthermore, to our knowledge, there is no strong evidence of depression-like or manic-like behavioral phenotypes in these mice. As most studies in $\mathrm{rl} /+$ mice have been conducted under basal conditions, we tested whether environmental stressors could uncover a behavioral phenotype. However, we found no differences between reeler heterozygous and WT mice in any of the paradigms tested. The absence of difference could be attributable to compensatory effects that commonly prevent the development of a phenotype in heterozygous mice. To overcome this, it would be interesting to repeat these behavioral tests in Reelin conditional knock-out mice. Our results are consistent with those of several other studies reporting no differences between $\mathrm{rl} /+$ and WT mice in the OF and BW tests (Podhorna and Didriksen, 2004) and in the FST with or without corticosterone treatment (Lussier et al, 2010). It is worth noting that discrepancies in the detection of PPI deficits in the $\mathrm{rl}+$ might result from differences in the experimental setup as referred to in (Barr et al, 2008). In that study, the investigators show deficits in cross-modal PPI in $\mathrm{rl} /+$ but no deficits in acoustic PPI, the procedure we used. In our study, in addition to following a downregulation strategy, we also studied the function of Reelin using the reverse approach, that is, Reelin overexpression. Using this novel approach, not only did we overcome the motor deficits found in the reeler mice but we also show a potential therapeutic use of Reelin pathway activation. Interestingly, Reelin overexpression had only a mild effect on anxiety-related behaviors under basal conditions (a reduction of anxiety-like behavior in the BW box). Psychiatric disorders are believed to result from a combination of genetic and environmental factors. Therefore, we proceeded to test whether Reelin protects against environmental insults. After exposure to chronic corticosterone treatment (a stress-associated hormone), Reelin-OE mice spent less time than WT mice floating in the FST, a paradigm that intents to model the development of helplessness behavior-characteristic of depression in humans - after chronic stress, and that has predictive value for the efficacy of antidepressants. In addition, in the presence of Ifenprodil (NR2B antagonist), slice recordings from corticosterone-treated WT animals showed a significantly higher reduction in fEPSPs than those of nonstressed WT animals. In contrast, fEPSPs of corticosteronetreated Reelin-OE mice slices were similar to those of WT non-stressed controls. Given that NR2B antagonists act as antidepressants (Li et al, 2010), we propose that Reelin may increase resilience to stress-induced behavioral dysfunctions through the downregulation of NR2B-mediated transmission.

Diseases like schizophrenia, mood, and anxiety disorders have high comorbidity levels. For instance, it has been reported that depression has a prevalence of $50 \%$ over the lifetime of schizophrenic patients (Altamura et al, 2011). Interestingly, we found that Reelin overexpression not only prevents behavioral dysfunctions after chronic 
corticosterone treatment, but also decreases hyperlocomotion induced by cocaine and PPI deficits induced by MK801. Both of these tests - cocaine-induced hyperlocomotion and PPI deficits induced by NMDA antagonists - are used as models of positive symptoms of schizophrenia (Geyer and Markou, 1995; van den Buuse, 2010) and show predictive validity of the effects of antipsychotic and moodstabilizing medication, as well as face validity in the case of PPI deficits (Geyer and Markou, 1995; Nestler and Hyman, 2010). It is fairly well established that the Reelin signaling pathway leads to Gsk- $3 \beta$ phosphorylation at Ser9, thereby leading to its enzymatic inhibition (Beffert et al, 2002). Several studies have reported that other candidate genes for mental illness, such as DISC1 (Mao et al, 2009) and Neuregulin 1 (Fazzari et al, 2010), regulate behavior through Gsk-3 $\beta$ inhibition. It is therefore possible that some of the behavioral effects of Reelin overexpression are due to Gsk-3 $\beta$ inhibition. In fact, lithium, a Gsk-3 $\beta$ inhibitor commonly used to treat bipolar disorder, also decreases psychostimulant-induced hyperlocomotion (Beaulieu et al, 2009).

In summary, here we show that the overexpression of Reelin in the mouse forebrain protects against the effects of chronic corticosterone and psychostimulant treatments. These observations indicate that this pathway may be an important therapeutic drug target.

\section{ACKNOWLEDGEMENTS}

We thank Lucas Brunso, Roberto Cabrera and the Cajal Physiolomic Unit for technical assistance, Anne Wheeler, Michel van den Oever, Scellig Stone and Paul Frankland for helpful comments, and Tanya Yates for editorial corrections. This work was supported by grants from CIBERNED, Plan Nacional de Drogas, Caixa Catalunya Foundation (Obra Social), MICINN and INCRECyT (European Social Fund and JCCM).

\section{DISCLOSURE}

The authors declare no conflict of interest.

\section{REFERENCES}

Altamura AC, Serati M, Albano A, Paoli RA, Glick ID, Dell'osso B (2011). An epidemiologic and clinical overview of medical and psychopathological comorbidities in major psychoses. Eur Arch Psychiatry Clin Neurosci; e-pub ahead of print 18 February 2011.

Barr AM, Fish KN, Markou A, Honer WG (2008). Heterozygous reeler mice exhibit alterations in sensorimotor gating but not presynaptic proteins. Eur J Neurosci 27: 2568-2574.

Beaulieu JM, Gainetdinov RR, Caron MG (2009). Akt/GSK3 signaling in the action of psychotropic drugs. Annu Rev Pharmacol Toxicol 49: 327-347.

Beffert U, Morfini G, Bock HH, Reyna H, Brady ST, Herz J (2002). Reelin-mediated signaling locally regulates protein kinase B/Akt and glycogen synthase kinase 3beta. J Biol Chem 277: 4995849964.

Belforte JE, Zsiros V, Sklar ER, Jiang Z, Yu G, Li Y et al (2009). Postnatal NMDA receptor ablation in corticolimbic interneurons confers schizophrenia-like phenotypes. Nat Neurosci 13: 76-83.

Boeuf J, Trigo JM, Moreau PH, Lecourtier L, Vogel E, Cassel JC et al (2009). Attenuated behavioural responses to acute and chronic cocaine in GASP-1-deficient mice. Eur J Neurosci 30: 860-868.

Braff DL, Geyer MA, Swerdlow NR (2001). Human studies of prepulse inhibition of startle: normal subjects, patient groups, and pharmacological studies. Psychopharmacology (Berl) 156: 234-258.

Brigman JL, Padukiewicz KE, Sutherland ML, Rothblat LA (2006). Executive functions in the heterozygous reeler mouse model of schizophrenia. Behav Neurosci 120: 984-988.

Chen Y, Beffert U, Ertunc M, Tang TS, Kavalali ET, Bezprozvanny I et al (2005). Reelin modulates NMDA receptor activity in cortical neurons. J Neurosci 25: 8209-8216.

Coyle JT (1996). The glutamatergic dysfunction hypothesis for schizophrenia. Harv Rev Psychiatry 3: 241-253.

D’Arcangelo G, Miao GG, Chen SC, Soares HD, Morgan JI, Curran $\mathrm{T}$ (1995). A protein related to extracellular matrix proteins deleted in the mouse mutant reeler. Nature 374: 719-723.

Fatemi SH, Earle JA, McMenomy T (2000). Reduction in Reelin immunoreactivity in hippocampus of subjects with schizophrenia, bipolar disorder and major depression. Mol Psychiatry 5: 654-663, 571.

Fatemi SH, Reutiman TJ, Folsom TD (2009). Chronic psychotropic drug treatment causes differential expression of Reelin signaling system in frontal cortex of rats. Schizophr Res 111: 138-152.

Fazzari P, Paternain AV, Valiente M, Pla R, Lujan R, Lloyd K et al (2010). Control of cortical GABA circuitry development by Nrg1 and ErbB4 signalling. Nature 464: 1376-1380.

Geyer MA, Markou A (1995). Animal models of psychiatric disorders. In: Bloom FE, Kupfer DJ (eds). Psychopharmacology: The Fourth Generation of Progress. Raven Press: New York. pp 787-798.

Goes FS, Willour VL, Zandi PP, Belmonte PL, MacKinnon DF, Mondimore FM et al (2010). Sex-specific association of the Reelin gene with bipolar disorder. Am J Med Genet B Neuropsychiatr Genet 153B: 549-553.

Gourley SL, Kiraly DD, Howell JL, Olausson P, Taylor JR (2008). Acute hippocampal brain-derived neurotrophic factor restores motivational and forced swim performance after corticosterone. Biol Psychiatry 64: 884-890.

Gourley SL, Taylor JR (2009). Recapitulation and reversal of a persistent depression-like syndrome in rodents. Curr Protoc Neurosci 9. Unit 932.

Groc L, Choquet D, Stephenson FA, Verrier D, Manzoni OJ, Chavis $P$ (2007). NMDA receptor surface trafficking and synaptic subunit composition are developmentally regulated by the extracellular matrix protein Reelin. J Neurosci 27: 10165-10175.

Herz J, Chen Y (2006). Reelin, lipoprotein receptors and synaptic plasticity. Nat Rev Neurosci 7: 850-859.

Hong SE, Shugart YY, Huang DT, Shahwan SA, Grant PE, Hourihane JO et al (2000). Autosomal recessive lissencephaly with cerebellar hypoplasia is associated with human RELN mutations. Nat Genet 26: 93-96.

Jia P, Sun J, Guo AY, Zhao Z (2010). SZGR: a comprehensive schizophrenia gene resource. Mol Psychiatry 15: 453-462.

Kessler RC, Chiu WT, Demler O, Merikangas KR, Walters EE (2005). Prevalence, severity, and comorbidity of 12-month DSMIV disorders in the National Comorbidity Survey Replication. Arch Gen Psychiatry 62: 617-627.

Kim HM, Qu T, Kriho V, Lacor P, Smalheiser N, Pappas GD et al (2002). Reelin function in neural stem cell biology. Proc Natl Acad Sci USA 99: 4020-4025.

Kim S, Webster MJ (2009). The Stanley neuropathology consortium integrative database: a novel, web-based tool for exploring neuropathological markers in psychiatric disorders and the biological processes associated with abnormalities of those markers. Neuropsychopharmacology 35: 473-482.

Krishnan V, Nestler EJ (2008). The molecular neurobiology of depression. Nature 455: 894-902. 
Krueger DD, Howell JL, Hebert BF, Olausson P, Taylor JR, Nairn AC (2006). Assessment of cognitive function in the heterozygous reeler mouse. Psychopharmacology (Berl) 189: 95-104.

Krystal JH, Karper LP, Seibyl JP, Freeman GK, Delaney R, Bremner JD et al (1994). Subanesthetic effects of the noncompetitive NMDA antagonist, ketamine, in humans. Psychotomimetic, perceptual, cognitive, and neuroendocrine responses. Arch Gen Psychiatry 51: 199-214.

Li N, Lee B, Liu RJ, Banasr M, Dwyer JM, Iwata M et al (2010). mTOR-dependent synapse formation underlies the rapid antidepressant effects of NMDA antagonists. Science 329: 959-964.

Li Y, Luikart BW, Birnbaum S, Chen J, Kwon CH, Kernie SG et al (2008). TrkB regulates hippocampal neurogenesis and governs sensitivity to antidepressive treatment. Neuron 59: 399-412.

Liu Y, Chen PL, McGrath J, Wolyniec P, Fallin D, Nestadt G et al (2010). Replication of an association of a common variant in the Reelin gene (RELN) with schizophrenia in Ashkenazi Jewish women. Psychiatr Genet 20: 184-186.

Lussier AL, Caruncho HJ, Kalynchuk LE (2009). Repeated exposure to corticosterone, but not restraint, decreases the number of reelin-positive cells in the adult rat hippocampus. Neurosci Lett 460: 170-174.

Lussier AL, Romay-Tallon R, Kalynchuk LE, Caruncho HJ (2010). Reelin as a putative vulnerability factor for depression: examining the depressogenic effects of repeated corticosterone in heterozygous reeler mice. Neuropharmacology 60: 1064-1074.

Maeng S, Hunsberger JG, Pearson B, Yuan P, Wang Y, Wei Y et al (2008). BAG1 plays a critical role in regulating recovery from both manic-like and depression-like behavioral impairments. Proc Natl Acad Sci USA 105: 8766-8771.

Mao Y, Ge X, Frank CL, Madison JM, Koehler AN, Doud MK et al (2009). Disrupted in schizophrenia 1 regulates neuronal progenitor proliferation via modulation of GSK3beta/betacatenin signaling. Cell 136: 1017-1031.

Martin ED, Buno W (2003). Caffeine-mediated presynaptic longterm potentiation in hippocampal CA1 pyramidal neurons. J Neurophysiol 89: 3029-3038.

Mayford M, Bach ME, Huang YY, Wang L, Hawkins RD, Kandel ER (1996). Control of memory formation through regulated expression of a CaMKII transgene. Science 274: 1678-1683.

Miyakawa T, Leiter LM, Gerber DJ, Gainetdinov RR, Sotnikova TD, Zeng $\mathrm{H}$ et al (2003). Conditional calcineurin knockout mice exhibit multiple abnormal behaviors related to schizophrenia. Proc Natl Acad Sci USA 100: 8987-8992.

Nestler EJ, Hyman SE (2010). Animal models of neuropsychiatric disorders. Nat Neurosci 13: 1161-1169.

Podhorna J, Didriksen M (2004). The heterozygous reeler mouse: behavioural phenotype. Behav Brain Res 153: 43-54.

Pujadas L, Gruart A, Bosch C, Delgado L, Teixeira CM, Rossi D et al (2010). Reelin egulates postnatal neurogenesis and enhances spine hypertrophy and long-term potentiation. J Neurosci 30: 4636-4649.

Qiu S, Korwek KM, Pratt-Davis AR, Peters M, Bergman MY, Weeber EJ (2006a). Cognitive disruption and altered hippocampus synaptic function in Reelin haploinsufficient mice. Neurobiol Learn Mem 85: 228-242.

Qiu S, Zhao LF, Korwek KM, Weeber EJ (2006b). Differential reelin-induced enhancement of NMDA and AMPA receptor activity in the adult hippocampus. J Neurosci 26: 12943-12955.

Salinger WL, Ladrow P, Wheeler C (2003). Behavioral phenotype of the reeler mutant mouse: effects of RELN gene dosage and social isolation. Behav Neurosci 117: 1257-1275.

Santarelli L, Saxe M, Gross C, Surget A, Battaglia F, Dulawa S et al (2003). Requirement of hippocampal neurogenesis for the behavioral effects of antidepressants. Science 301: 805-809.

Shifman S, Johannesson M, Bronstein M, Chen SX, Collier DA, Craddock NJ et al (2008). Genome-wide association identifies a common variant in the reelin gene that increases the risk of schizophrenia only in women. PLoS Genet 4: e28.

Tissir F, Goffinet AM (2003). Reelin and brain development. Nat Rev Neurosci 4: 496-505.

Torrey EF, Barci BM, Webster MJ, Bartko JJ, Meador-Woodruff JH, Knable MB (2005). Neurochemical markers for schizophrenia, bipolar disorder, and major depression in postmortem brains. Biol Psychiatry 57: 252-260.

Tost H, Lipska BK, Vakkalanka R, Lemaitre H, Callicott JH, Mattay VS et al (2010). No effect of a common allelic variant in the reelin gene on intermediate phenotype measures of brain structure, brain function, and gene expression. Biol Psychiatry 68: 105-107.

Tueting P, Costa E, Dwivedi Y, Guidotti A, Impagnatiello F, Manev $\mathrm{R}$ et al (1999). The phenotypic characteristics of heterozygous reeler mouse. Neuroreport 10: 1329-1334.

van den Buuse M (2010). Modeling the positive symptoms of schizophrenia in genetically modified mice: pharmacology and methodology aspects. Schizophr Bull 36: 246-270.

Wong TP, Howland JG, Robillard JM, Ge Y, Yu W, Titterness AK et al (2007). Hippocampal long-term depression mediates acute stress-induced spatial memory retrieval impairment. Proc Natl Acad Sci USA 104: 11471-11476.

Zhao C, Deng W, Gage FH (2008). Mechanisms and functional implications of adult neurogenesis. Cell 132: 645-660.

(c) This work is licensed under the Creative SOWERाHWISBRESERVED Commons Attribution-NonCommercial-No Derivative Works 3.0 Unported License. To view a copy of this license, visit http://creativecommons.org/ licenses/by-nc-nd/3.0/

Supplementary Information accompanies the paper on the Neuropsychopharmacology website (http://www.nature.com/npp) 